\title{
Los flujos de información: algunas reflexiones
}

\author{
Egbert Sánchez VANderkast \\ Hemerobiblioteca Dr. José Joaquín Izquierdo, Facultad de Medicina \\ de la UNAM, 04510, México D.F., Tel: 56-23-23-27 y 56-23-25-03 \\ E-mail: egbert@ servidor.unam.mx
}

\begin{abstract}
RESUMEN
Los flujos de información fueron un tema de estudio polémico durante los años ochenta. El interés por realizar estudios alrededor de este tema ha ido disminuyendo paulatinamente. D ebido al entorno cambiante, la manera en que actualmente se están dando estos flujos también ha cambiado.

Palabras claves: Flujos de información
\end{abstract}

\section{INFORMATION FLOW: SOME REFLECTIONS \\ EgBERT SÁNCHEZ-VANDERKAST}

\begin{abstract}
Information flow was a highly discussed theme during the eighties. G radually the interest around this subject has diminished. Although we cannot say that there is any flow ocurring at the moment, we can assume that the environment has undergone some changes

Keywords: Information Flow.
\end{abstract}

\section{INTRODUCCIÓN}

\begin{abstract}
e pretende aquí describir algunas de las tendencias de flujos de información durante los últimos treinta años. Para ello se analizaron varios autores que se consideraron representativos por sus aportaciones a nivel nacional e internacional. También se realizó una revisión de las interpretaciones que pudieran servir para entender esta temática. En este contexto se retomó el modelo clásico de comunicación de Shannon para ilustrar los diferentes tipos de flujos y algunas de sus características. Por último se intentará vincular esto con los estudios de información y vertir algunas reflexiones. No se incluyen aportaciones teórico-metodológicas en este documento ni una bibliografía relativa al tema.
\end{abstract}


Las políticas de información como área de estudio de la bibliotecología, la ciencia de la información y los estudios de la información han tenido poca difusión.

Amanda Spink ${ }^{1}$ y Peter Hernon ${ }^{2}$ la perciben como un área emergente delas disciplinas mencionadas en la que habrá que realizar estudios próximamente. Estos autores pronosticaron que a partir del 2000 las investigaciones alrededor del tema aumentarían y paulatinamente se consolidarián como un campo de acción de las disciplinas mencionadas. Lo anterior no se debe interpretar como que no ha habido "políticas de información".

En el ámbito educativo de América Latina laUNESCO ha promovido algunos lineamientos para establecer la infraestructura de bibliotecas, lo que se puede considerar como el punto de partida de lo que hoy se denomina "políticas de información". Sin embargo la literatura internacional indica que Hernon y Relyea fueron los primeros que hablaron de "políticas de información" como tales. Su enfoque trata el tema desde la perspectiva de la administración pública.

El resurgimiento del tema durante la década delos noventa como un tema emergente se debe a la convergencia entre diversas tecnologías, como las tecnologías de lainformación, la tecnología de la comunicación, la de cómputo, la microelectrónica y las telecomunicaciones. También la globalización de los mercados y el surgimiento delallamada sociedad de lainformación vienen a ser factores decisivos en el repunte del tema.

Con base en lo anteriormente expuesto surge la siguiente pregunta:

¿Qué ha pasado con el tema durante las últimas tres décadas?

Durante la década de los noventa los estudios sobre flujos de información han sido englobados en "políticas de información", pero siendo un campo de investigación poco explorado y con límite de acción poco delimitado el resultado ha sido frecuentes altibajos en los últimos treinta años. Como consecuencia una amplia cantidad de temas se han incorporado a políticas de información como subtemas de la misma.

Los subtemas dentro de la temática mencionada han sido tratados como tópicos del mismo por varios autores.

Bender ${ }^{3}$ ha englobado un total de diez tópicos de "políticas de información":

* Tecnologías de información

* Flujos de información transfronteras

* Privacía/ protección de datos personales

* Propiedad intelectual

* Comercio e industria de información en los sectores públicos y privados

1 Amanda Spink. "Information science in sustainable development and de-industrialization". Information Reserch 5 (1) :p. 23.

2 Peter Hernon. Editorial: "Library and Information Science reseach - marking the 20th anniversary". LibraryandInformation SäeneResenth 20 (4):p.309-20.

3 D avid Bender. "A strategy for international information policy". Libri 43 (3): p. 222-227. 
* Bibliotecas, archivos y acceso a la información

* Información científica y técnica

* Telecomunicaciones

* Normatividad

* Educación y capacitación

D e estos subtemas sólo se profundizará en los flujos de información trasfronteras, donde los pronunciamientos principales que dominaron los años setenta y los ochentas fueron:

I. la automatización, y

II. la era de la información.

\section{LOSFLUJOSDE INFORMACIÓN}

Para referirse a los flujos de información transfronteras se han utilizado indistintamente los términos siguientes:

* Flujo de datos transfronteras

* Flujo de información transfronteras

* Flujo transfronteras de datos

* Flujo transfronteras de información

Madec, ${ }^{4}$ estudioso del tema, sugiere quelo correcto es utilizar "intercambio internacional de información". Los flujos de información transfronteras se consideran movimientos de datos que traspasan los límites geográficos de los Estados como naciones desde un primer instante.

Autores como Almada de Ascencio (1984), Bender (1988), Cronin (1987), D onaghue (1983), D uchesne (1984), Eres (1989), Jussawalla (1984, 1987), Lauzon (1985), Mahon (1986), Morales Campos (1987), Olson (1977), O ma(1990), Renaud (1986), Suprenant (1987) y Vickers (1983) que han estudiado y analizado el tema presentan definiciones que varían el grado de complejidad desde "el flujo de información o datos que traspasan las fronteras nacionales..... a movimiento electrónico de datos que traspasan la frontera para el almacenamiento y/ o procesamiento por medio de una computadora".

Jusawalla y Ebenfield (1987) conceptualizan la noción desde una perspectiva economicista como: "el movimiento de datos que traspasan las fronteras nacionales con el propósito de procesary almacenar los datos para su recuperación con base en un contrato entre los interesados de dos o más naciones".

4 A. Madec. El mecadbintemaaional delainfomacón: losflujosdetransionterasdeinfomacionesydatos Madrid : Fundesco-Tecnos, 1984, p.15. 
Anteriormente Jusawalla en 1984 lo percibía como "la comunicación entre los sistemas de cómputo que traspasan las fronteras".

Mientras que Eres (1989) y Renaud (1986) señalan que el Centro de Corporaciones Transnacionales de la O rganización de las Naciones Unidas acepta como flujo de información trasfronteras "los movimientos de datos legibles por máquina, procesados y almacenados para su recuperación que traspasan las fronteras nacionales"; esto mientras se persiguen los fines específicos de esta corporación.

Brasil por su parte considera los flujos mencionados como "la transferencia de cualquier tipo de información sea ésta técnica, económica o cultural cruzando las fronteras nacionales". (D onaghue, 1983)

Por su parte Suprenant en sus Gldbal ThreatstoInfomationandproblens(1985) y en TrendsinIntemational andCommmicationPdicies(1987)lo define como "los movimientos de datos que traspasan fronteras que son legibles por máquina para el procesamiento, almacenamiento y recuperación de los mismos, que abarca los transmitidos electrónicamente pormedio de sistemas de cómputo y de comunicaciones". El concepto mencionado comprende tres elementos clave para realizar algún flujo electrónico: los sistemas de cómputo, las redes de telecomunicaciones y los datos.

En la actualidad la Internet tiene sus fundamentos en los sistemas de cómputo, las telecomunicaciones y los contenidos.

Estos contenidos comprenden:

1. los servicios de datos disponibles por medio de bancos de datos, videotexto, publicaciones electrónicas, video, imagen audio y los multimedios,

2. datos de índole financiera y bursátil que apoyan el comercio internacional,

3. la información gubernamental y la no gubernamental.

Mientras tanto Mowlana ${ }^{5}$ por su parte considera que los flujos de información son "el movimiento de mensajes que traspasa las fronteras nacionales de dos o más naciones, grupos étnicos o culturales".

Los flujos de información internacional han sido objeto de estudio con base en distintas ópticas: comunicación, relaciones internacionales, ciencias sociales y turismo. Estas disciplinas consideran a los flujos como "un campo de acción que estudia la transferencia de datos, así como también la transferencia de tecnologías, las influencias de éstas sobre los individuos, los grupos sociales, los gobiernos y las estructuras de las instituciones"6. Pero también estudia la promoción, la difusión y la calidad de los mensajes (información) entre las naciones, los pueblos y la cultura.

El estudio de los flujos de información en este sentido abarcaría aspectos distintos y líneas de investigación torales como:

1. Las relaciones internacionales

2. Las relaciones comerciales

5 H. Mowlana. Gldbal informationandwordcommmication: nevfrontiesinintemational redations New Y ork : Longman, 1986. P.15.

6 Mowlana. OpCit p.20 
3. Los sistemas de comunicación

4. La comunicación

5. El desarrollo social

6. Las leyes

7. La tecnología

8. La bibliotecología

Cada uno de estos rubros ha sido influido por la microelectrónica y la ingeniería de cómputo de una u otra forma. D ebido a la explosión de la información la adaptación eincursión de esta ingeniería en el ámbito bibliotecario para agilizar algunos de los procesos de las bibliotecas, dio auge a lo que se conoció como la automatización de las bibliotecas en los años setenta.

En la década de los ochenta los estudios sobre flujos de información giraron alrededor de la economía de la información y de sus infraestructuras.

La economía de la información como área de investigación ha analizado la infraestructura de la información y de la comunicación enfocándose a elementos tales como los productos y su distribución y la optimización de los recursos económicos, humanos y tecnológicos. Esta área de investigación concentró su esfuerzo en establecer comunicaciones a distintos niveles: realizar análisis de las distribuciones, estudiar el costo/ beneficio y examinar la utilidad real de los productos que emanen de las fuentes de información.

La infraestructura de comunicación comprendida desde la perspectiva de los estudios de lainformación, es la base para conducir a cualquier país hacia un desarrollo socioeconómico equitativo. En este sentido los avances registrados en telemática, telecomunicaciones y tecnologías de redes han sido impulsores de los flujos de información a nivel regional e internacional. Con todo siguen prevaleciendo situaciones de índole tecnológica, semántica y humana que en algunos casos podrían entorpecer las transferencias de la información y de los datos, pero esta situación ha ido en decremento.

La infraestructura de la información está de una forma u otra interrelacionada con la generación y distribución de la información. A la vez actúa como agilizadora de la transmisión de datos e información tanto por medios convencionales como electrónicos. A partir de lo anterior autores como Zurkowski y Horton elaboraron una metodología para realizar análisis sobre los flujos de información desde la perspectiva de la industria de la información por medio de un mapa plano.

La propuesta de análisis de Zurkowski toma como eje la computadora y alrededor de este instrumento posiciona verticalmente los servicios y los productos de información, mientras que coloca de manera horizontal los medios y los contenidos.

Por su parte, Horton adapta lo anterior a la gestión y administración de la información (information management) utilizando una distribución diferente a la de Zurkowski para realizar el análisis de los flujos de información donde él también toma la computadora como eje. D istribuye lo relacionado con los medios/ canal/ contenido 
de manera horizontal en tanto que todo lo relacionado con las funciones/ manejo/ propiedad lo representa de manera vertical.

El concepto de compartir recursos y fuentes de información aunado a los avances hechos en la utilización de tecnologías de la comunicación, y posteriormente la implementación de las telecomunicaciones en los centros de información le han dado el empuje a la transferencia de información por los medios telemáticos.

La llamada era de la información se ha caracterizado por lo siguiente:

1. la implantación de infraestructuras nacionales de información,

2. el mantenimiento de operación de las redes telemáticas,

3. la formación masiva de recursos humanos de toda índole en el uso y apropiación de las tecnologías, y

4. la actualización de los profesionales y técnicos en el área de información.

En esta era de la información en la que también surgió la glo balización económica la atención en materia de información ha estado centrada en las discuciones engendradas alrededor del control sobre los datos y la información, el uso de la tecnologías, y los impactos de los flujos de datos trasfronteras en los países.

\section{EL MODELO DE COMUNICACIÓN DE SHANNON}

Shannon se ha preocupado por los problemas de la ingeniería y propuesto una ecuación matemática de la información tomando en cuenta su aplicación con base en los costos y el incremento de la comunicación.

$$
\mathrm{I}=\mathrm{KIn} / \mathrm{p}
$$

En este caso Irepresentalainformación, laKes la constante y la Ines el logaritmo natural con base en $\mathrm{E}$.

Se resenta la definición de la información como "el logaritmo negativo de cantidades de posibles mensajes en un conjunto, siendo que todo los mensajes tienen la misma posibilidad de ser elegidos".7

Weaver interpreta la teoría propuesta por Shannon a partir de una perspectiva técnica, semántica y psico-conductual. (Ver: Figura 1.)

Realiza la distinción de tres niveles de posibles problemas en la comunicación y aborda la información en sus partes técnica, semántica y psico-conductual.

Con base en la ingeniería y las leyes de la termodinámica presenta la fórmula:

$$
\text { Infomadón = negatroṕa }
$$

0

$$
\text { Infomadón = ettropía }
$$

D onde la información es la organización, todo lo contrario ala entropía, que es el caos.

7 C. Shannon y W. Weaver. Themathematical theery of comminication Urbana, Chicago, London : University of Illinious Press, 1949. P. 26. 
Figura 1. Niveles de comunicación

\section{NIVELES DE COMUNICACIÓN}
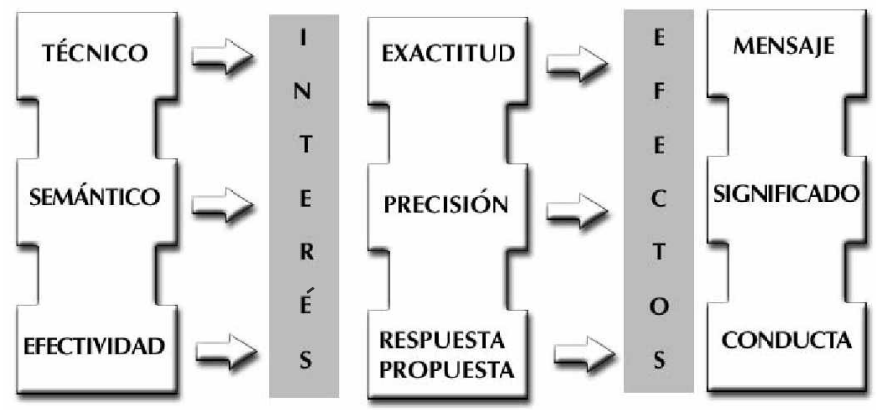

Figura 1. Fuente: Pao, M.L. (1989). Concepts of information retrieval. Englewood, Col.: Libraries Unlimited

Los problemas de índole técnica pueden afectar la medida de la precisión de los mensajes transmitidos y también la recepción del mismo por parte del destinatario.

Siguiendo el modelo $\mathrm{E}-\mathrm{M}-\mathrm{M}$, en la parte semántica incurre en el cuestionamiento ¿qué tan preciso son los vocabularios utilizados para describir algo o un cosa?

Una interpretación de lo anterior es la siguiente a partir de la selección de una fuente ideal. Una fuenteideal de información tieneinfinidades de respuestas paraun tema. (ver: Figura 2)

Figura 2. Fuente ideal de información

\section{FUENTE DE INFORMACIÓN IDEAL}

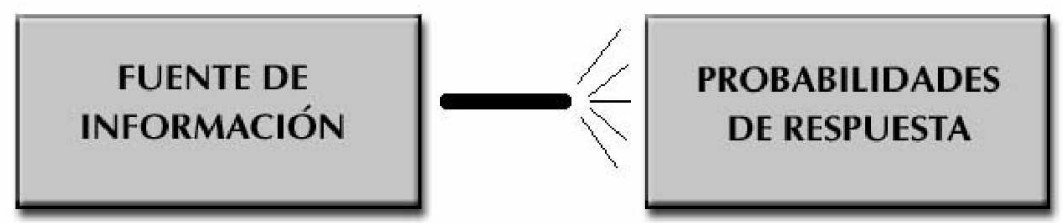

Figura 2. Fuente: Raisbeck, G. (1963). Information theory: an introduction for scientist and engineers. Cambridge, Mass: MIT 
Telemáticamente hablando una fuente de información ideal es "un conjunto compuesto por caracteres que tiene " $n$ " posibilidades de mensajes". (D olby,1984)

Pero tener resueltos los dos parámetros anteriores no asegura la comunicación efectiva. Si se logró tal propósito es algo que se verá reflejado en las toma de decisiones y la transformación de conductas de los sujetos.

Entonces el emisor se traduce como; insumo, mensajes, preguntas y el receptor en; salida mensaje, problema resuelto/ toma de decisiones.

Shannon en su diagrama general de sistemas de comunicación lo representa de la siguiente manera: siempre habrá una fuente de información - transmisor - ruido en el canal - un receptor - destino, y a través de estos elementos transcurre un mensaje. (Ver: Figura 3.)

Figura 3. Problemas de comunicación

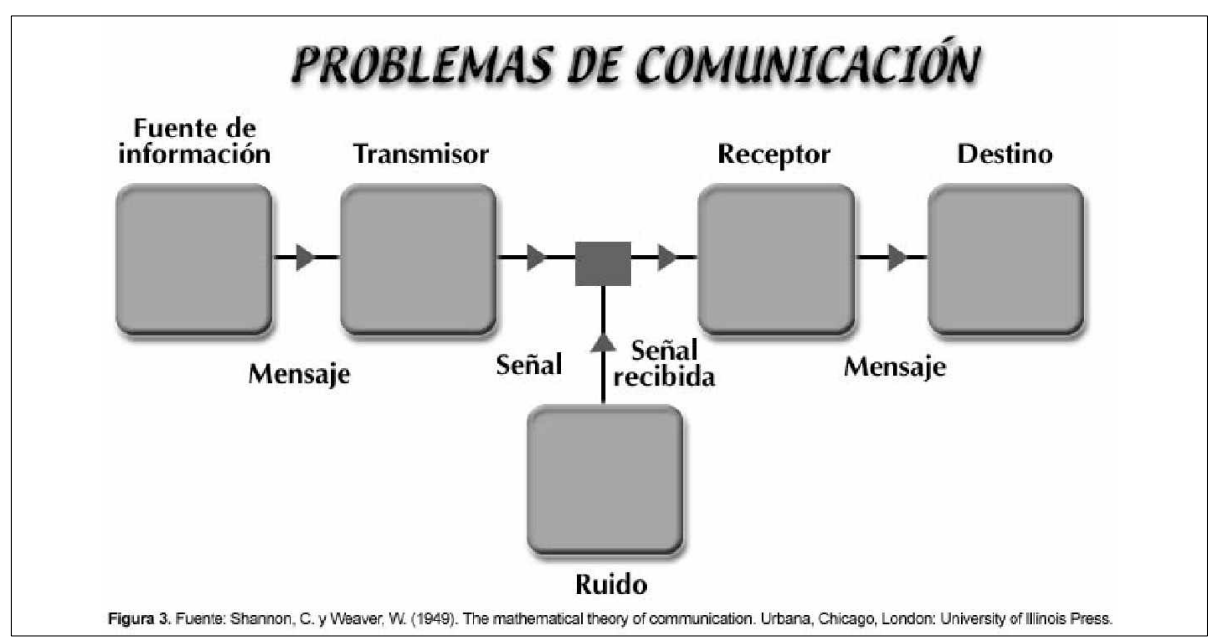

\section{CATEGORIZACIÓN DE LOSFLUJOSDE INFORMACIÓN}

De acuerdo con este modelo, los flujos de información se dan cuando existe un emisory un receptor. Los flujos pueden ser de humano a humano, de humano a má quina, y de máquina a máquina.

O tras categorizaciones de los flujos de información pueden ser las siguientes:

I. Tipo de flujo, uni-direccional, bi-direccional y multidireccional, como en el caso de la red Internet.

II. Tipo de orientación; a) científico-técnica. Las investigaciones según esta orientación giran alrededor de las telecomunicaciones, la comunicación vía satelite, laradio y la televisión. Abarca también la comercialización de películas, grabaciones sonoras, videos, los multimedios y los formatos digitales. La nuevas formas de impresión y publicación de materiales bibliográficos, hemerográficos y sonoros. 
b) humanística. Existe aquí más flexibilidad y el énfasis está puesto en el intercambio cultural, artístico y educativo. Esta orientación abarca también los canales diplomáticos, políticos, los eventos de organismos gubernamentales y no gubernamentales (como son los congresos, conferencias y seminarios que organizan estas identidades) y la comunicación entre pares y el turismo en general.

III. Tipo de contenido. El contenido dela información varía considerando las necesidades de los usuarios finales y puede ser muy específico como: a) los datos de operaciones que apoyan la organización en la toma de decisiones; b) las transacciones financieras; c) datos personales; d) datos científico-técnico y humanísticos (experimentos, datos estadísticos, numéricos y gráficos, mediciones ambientales y meteorológicas, datos referenciales y bibliográficos, programas y utilerías de cómputo).

IV . Disponibilidad. Ésta puede obtenerse en línea, en disco-compacto, en cinta disco magnético o impresos, electrónica o en forma digital.

V. Tipo de actores. Éstos se agrupan en tres grandes rubros: el go bierno, las organizaciones no gubernamentales y privadas, y el público en general .

VI. Tipo de datos/ información. O rna (1990)8 lo describe de la siguiente manera: a) datos operativos relativos a la producción documental generada en la institución; b) datos administrativos: estadísticas, análisis; c) informe técnico; d) encuesta; e) datos comerciales.

O tros elementos a considerar en los flujos de datos son:

* Disponibilidad

* Accesibilidad

* Autenticidad

* Compatibilidad

* Diversificación

* Eficiencia

* Equidad en la atención de los usuarios

* Integración, interactividad y operación

* Respeto de los datos personales

* Confiabilidad y facilidad de uso.

Para que se dé algún flujo de información necesita haber un emisor y su respectivo receptor.

Extrapolando este modelo a un ambiente telemático tenemos el emisor o etapa de producción que consiste en las fuentes y/ o los comunicadores, y en la formación de los mensajes; y la etapa de distribución que está compuesta por la distribución de los mensajes y los destinatarios. En estas dos etapas intervienen por igual la tecnología de la información y de la comunicación, los programas de cómputo, el protocolo

8 Elizabeth O rna. Practical Information policies: how to manage information flow of organization. Worchester:G ower 
de transmisión de datos y las telecomunicaciones, y se propician las transferencias de datos, imagen, texto y voz en general. (Ver: Figura 4)

\section{Modelo de flujo de información telemático}

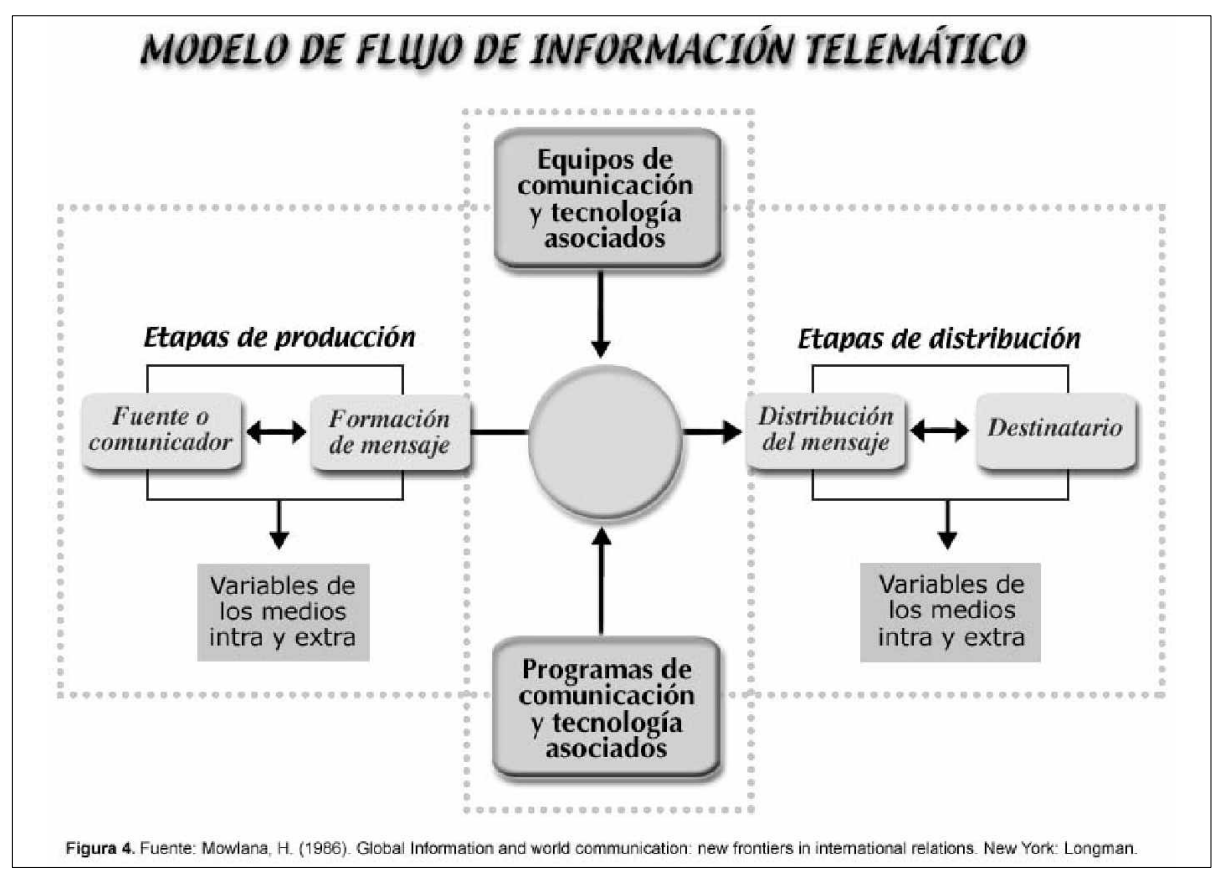

A demás en cualquiera de las etapas anteriormente mencionadas intervienen algunos medios que suelen ser externos o internos y que pueden ir desde la autoría hasta los tipos de contenidos que se van a generar.

O tros factores que cabe considerar en cualquier tipo de flujo deinformación son:

1. el constante desarrollo de las tecnologías;

2. el impacto de los flujos de información en las instituciones tanto públicas como privadas;

3. las fusiones en la industria de la información;

4. El creciente interés de promover un mejor acopio y recuperación de documentos y datos;

5. las actividades del mercado económico denominado la globalización;

6. las actividades entorno a las políticas sociales de los estados-naciones;

7. las grandes inversiones en telecomunicaciones;

8. los impactos de la información en la toma de decisiones, considerada ésta como el cuarto poder económico, y 
9. las actividades y las declaraciones en torno a "políticas de información" que agrupan tanto a la información como a las telecomunicaciones.

\section{LOSFLUJOSDE INFORMACIÓN EN LOSESTUDIOSDE INFORMACIÓN}

Los flujos de información en las bibliotecas se dan de humano a humano a partir de la solicitud de un servicio por parte de algún usuario que asista a la biblioteca. $\mathrm{Al}$ solicitar una información el usuario espera una respuesta para solucionar a un problema o resolver una duda.

Siendo éste el emisor necesita que el personal que cumple con la función de referencista lo entienda o mejor dicho interprete sus necesidades de información.

Los usuarios potenciales en este caso representan a los emisores y el referencista asume papel de receptor.

En este contexto los emisores comprenden a: estudiantes, docentes, capacitadores, tutores, administradores, gestores, coordinadores, consultores, planeadores, tomadores de decisión, patrocinadores, investigadores, evaluadores, historiadores, educadores y editores. Cadauno de éstos tiene requerimientos distintosy las fuentes ideales de información para cada uno de los emisores son también diferentes.(Ver: Tabla 1.)

Tabla 1. Usuarios potenciales

\begin{tabular}{|l|l|l|}
\hline \multicolumn{1}{|c|}{$\begin{array}{c}\text { USUARIOS } \\
\text { POTENCIALS }\end{array}$} & \multicolumn{1}{c|}{$\begin{array}{c}\text { TIPOS DE } \\
\text { DOCUMENTO }\end{array}$} & \multicolumn{1}{c|}{ FUENTES } \\
\hline Estudiantes & Temarios & Organizaciones Nacionales \\
\hline $\begin{array}{l}\text { Docentes } \\
\text { Capacitadores } \\
\text { Tutores }\end{array}$ & $\begin{array}{l}\text { Tema de taller } \\
\text { Antologías } \\
\text { Material didáctico Temarios }\end{array}$ & Organizaciones regionales \\
\hline Administradores & Técnicas de administración & Agencias intergubernamentales \\
\hline $\begin{array}{l}\text { Gestores } \\
\text { Coordinadores } \\
\text { Consultores }\end{array}$ & $\begin{array}{l}\text { Herramientas de análisis } \\
\text { Métodos de avalar } \\
\text { Métodos de evaluación } \\
\text { Fuentes de patrocinio }\end{array}$ & $\begin{array}{l}\text { Organizaciones no gubernamen- } \\
\text { tales }\end{array}$ \\
\hline
\end{tabular}


Tabla 1. Usuarios potenciales

(Cont.)

\begin{tabular}{|l|l|l|}
\hline \multicolumn{1}{|c|}{$\begin{array}{c}\text { USUARIOS } \\
\text { POTENCIALES }\end{array}$} & \multicolumn{1}{c|}{\begin{tabular}{c}
\multicolumn{1}{c|}{ TIPOS DE } \\
DOCUMENTO
\end{tabular}} & \multicolumn{1}{c|}{ FUENTES } \\
\hline $\begin{array}{l}\text { Planeadores } \\
\text { Tomadores de decisión } \\
\text { Patrocinadores }\end{array}$ & $\begin{array}{l}\text { Compartir experiencia } \\
\text { Propuestas básicas } \\
\text { Métodos de mercadeo } \\
\text { Modelos de planeación } \\
\text { Exposición de directrices } \\
\text { Revisiones }\end{array}$ & $\begin{array}{l}\text { Centros de distribución } \\
\text { Redes } \\
\text { Bases de datos } \\
\text { Bibliotecas }\end{array}$ \\
\hline $\begin{array}{l}\text { Estudios } \\
\text { Información demográfica } \\
\text { Información socioeconómica }\end{array}$ & $\begin{array}{l}\text { Informe de investigación } \\
\text { Evaluadores } \\
\text { Historiadores } \\
\text { Educadores de enseñanza } \\
\text { superior } \\
\text { Editores }\end{array}$ & $\begin{array}{l}\text { Artículo de revista } \\
\text { Artículo de congreso } \\
\text { Fuentes históricas } \\
\text { Archivos / Registros } \\
\text { Información de análisis secun- } \\
\text { darios }\end{array}$ \\
\hline
\end{tabular}

Fuente: D osa, Marta (1997). Aarssall Bardess intemational flousandapplica tion Langham, Maryland. Scarecrow.

Lo anterior no significa que un emisor se limite solamente a una fuente ideal de información. También puede recurrir a otras fuentes ideales que vienen enunciadas en este cuadro.

Si en ese momento el proceso de comunicación tuviera éxito entonces no habría que aplicar la Estrategia de Entrevista O ptima, EEO .

LaEEO se da con el fin de reducir tanto el ruido como la incertidumbre que pudiera existir en la comunicación.

\section{Estrateeja deentrevista óptima = Recucción deniidb \\ Estrateeja deentreista óptima $=$ Reelurción deincertidumbre}

El emisor busca aquella información que lo apoyará en su investigación, su toma de decisiones, o a elevar la calidad de su vida y a resolver problemas.

En otras palabras el emisor persigue un proceso creativo que lo llevará a aplicar esos conocimientos adquiridos, difundirlos e impactar en el entorno. Este proceso creativo puede ser traducido en investigación, desarrollo, mercadeo o promoción y contribuciones a corto y mediano plazo. (Ver Tabla2.) 
Tabla 2. El proceso creativo

\begin{tabular}{|c|c|c|c|}
\hline $\begin{array}{l}\text { EL PROCESO } \\
\text { CREATIVO }\end{array}$ & APLICACIONES & $\begin{array}{l}\text { DIFUSIÓN DE LA } \\
\text { INNOVACIÓN }\end{array}$ & IMPACTO \\
\hline $\begin{array}{l}\text { Investigación } \\
\text { Políticas de información } \\
\text { Fondos para investigación } \\
\text { Becas } \\
\text { Psicología del proceso } \\
\text { creativo } \\
\text { Propiedad } \\
\text { Proceso de patentar } \\
\text { Marca registrada } \\
\text { Secreto } \\
\text { Tipo de secreto } \\
\text { Técnicas de proyección }\end{array}$ & $\begin{array}{l}\text { D esarrollo } \\
\text { Políticas de información } \\
\text { Brecha de conocimiento } \\
\text { Difusión de la investigación } \\
\text { Transferencia de tecnología: } \\
\text { - Local } \\
\text { - Extranjera } \\
\text { Países industrializados } \\
\text { Países en desarrollo } \\
\text { Leyes / Regulación } \\
\text { Agencias Federales }\end{array}$ & $\begin{array}{l}\text { Mercadeo } \\
\text { Políticas de Información } \\
\text { Estudio de mercado } \\
\text { Factores de difusión } \\
\text { Difusión de reconoci- } \\
\text { mientos públicos } \\
\text { Medios masivos } \\
\text { Interés público } \\
\text { Leyes } \\
\text { Consumismo } \\
\text { Reempaquetamiento de } \\
\text { información }\end{array}$ & $\begin{array}{l}\text { Contribución } \\
\text { Políticas de } \\
\text { información } \\
\text { Tecnología } \\
\text { Informe de impacto } \\
\text { Uso de indicadores: } \\
\text { - Social } \\
\text { - Salud } \\
\text { - Ambiental } \\
\text { Banco de datos } \\
\text { Diseño de modelos }\end{array}$ \\
\hline
\end{tabular}

Fuente: D osa, Marta. (1997) Acoossall bordess intemational informationflons andapplications Lanham, maryland: Scarecrow.

En este sentido la biblioteca como institución desempeña un rol como emisor. La estructura organizacional de la biblioteca como codificador/ decodificador. Por su parte el usuario interviene en su papel de destinatario/ receptor.

¿Q ué se busca? En un ambiente telemático.

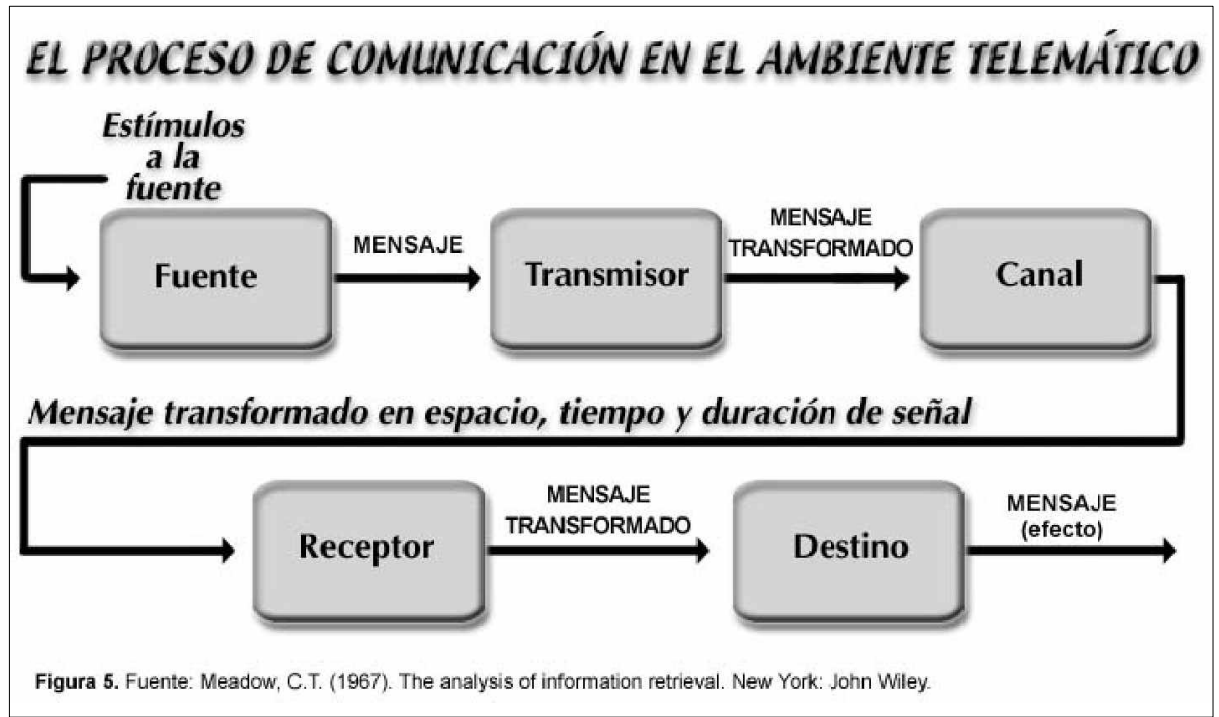


Considerando lared Internet como un ambiente telemático, lainterpretación de alguna necesidad por medio de buscadores nos llevará sin duda alguna a fuentes ideales de información. Estas fuentes pueden ser tanto institucionales como personales. Los motivos que inducen al emisor a recurrir a estas fuentes podrán ser múltiples.

En un ambiente telemático en donde la interacción que prevalece es la de humano-máquina, los emisores tienen una doble función ser el usuario/ emisor y ser codificador/ decodificador de las páginas electrónicas. Esto con el fin de seleccionar la(s) página(s) electrónica(s) que semánticamente hablando se apegue(n) a sus necesidades.

En este orden de ideas las páginas electrónicas en su etapa de producción deben tener una estructura organizativa que refleje no solamente la institución representada sino también los contenidos que forman parte de su colección.

En la etapa de distribución se reflejará la identidad de una página en la que intervienen los medio internos y externos, que son las publicaciones propias de las instituciones y que se ponen a disposición de todo público.

Una página electrónica como fuente ideal de información siempre deberá estar enfocada hacia la comunidad a la que atienda. D onde la satisfacción de " $n$ " necesidades de información puede ser atendida con éxito.

D ado lo anterior lo que se tendrá que ir buscando en materia de flujos de información no es la parte tecnológica, sino más bien la relacionada con el contenido.

Considero que los flujos de información entre maquinas y entre máquina-máquina estarán resueltos siempre y cuando haya compatibilidad entre los programas y protocolos. La mayor parte de los problemas han podido ser superados con nuevos programas y utilerías que evolucionan en forma vertiginosa.

\section{ALGUNAS REFLEXIONES.}

Los estudios revisados en el presenteescrito sobre flujos de información durante los años ochenta muestran una característica altamente técnica. D ado lo anterior la ingerencia de la tecnología y su rápida evolución han dirigido todo los estudios hacia la tecnología. La técnica siempre surge cuando hay una necesidad, lo que se denota con la explosión de la información durante los años setenta que generó "cuellos de botella" tanto en la organización del conocimiento como en la recuperación de los documentos. Una de las salidas fue recurrir a la automatización de los procesos bibliotecarios y a la comunicación del conocimiento generado. Los flujos de información hombre-hombre necesitaban ser agilizados. Tal como lo demandaba el rezago en el procesamiento de los materiales bibliagráficos y la lenta recuperación de la información y de los documentos requeridos. El abaratamiento de la tecnología de la computación y sus aplicaciones al quehacer bibliotecario provocaban un cambio en los flujos de informacion de hombre-hombre a hombre-máquina.

Ante este panorama considero que aún hay que explorar el estudio de los flujos de información desde nuevas ópticas. 
Por ejemplo ¿cómo se dan los flujos de información en diferentes comunidades de usuarios potenciales?

D eigual manera, tomando como referente el modelo de flujo de información telemático:

* ¿Cuáles son los medios internosy externos que se imponen en cada etapa de los flujos?

¿Cuáles son los elementos eje en los flujos de información: a) hombre-hombre, b)hombre-máquina, c) máquina-máquina?

Las respuestas a cada una de las interrogantes aquí planteadas arrojarán propuestas conceptuales y nos llevarán a construir modelos descriptivos para entender mejor los flujos de información en una nueva etapa que seguramente superará las añoranzas de los años ochenta.

\section{REFERENCIAS BIBLIOGRÁFICAS}

Almada de Ascencio, M. "Flujos Transfronteras", en Memrias de Coloquio Infomática, LegisladónY DesarrdloNaainal. Méxic, D.F.: Senadodela Répública p.227-238.1984.

Bender, D. "A strategy for international information policy". Libri 43 (3): p. 210-231.

Cronin, B. "Telematics and retribalization" . A sibProweedings39: 8795. 1987a

Cronin, B. "Transatlantic perspectives on information policy: the search for regulatory realism". Jaumal of Infomation Saiene 13: 129-138. 1987b.

D olby J. "D ata as information". Information ProcessingManagenent. 20. 1984.

D onaghue, H. "Implication of transborder data flows to library networks". IFLA Jaumal. 12: 34-38. 1986.

D osa, Marta. Acossall bordes intemational informationflousandapdica tions Lanham : Scarecrow. 1997.

D uchesne, R. "Transborder data Flow". IFLA Jaumal. 12:317-321.

Eres, B.K. "Transfer of information technologies to developed countries: a system approach". Joumal oftheammicanSoidyforInformation Saience 32 : 97-102.

Hernon, P. "Editorial: library and information science research marking the journal's 20th anniversary". Library and information SaienceResearch 20 : 309-320. 1998.

Jussawalla, M. y Ebenfield, H. Commmicationandinfomationeconomics Newpespetives Amsterdam: North Holland. 1984. 
Jussawalla, M. y Cheah, C.W. Thecalatusofintemational commmications astudyof pditical ecomomy oftransborder dataflowLittleton, Col.: Libraries Unlimited. 1987.

Lauson, J. "Les flux tansfrontieres de données". Doometation \&Bibiotheques $31:$ 101-105. 1985.

Mahon, B. "Transborder data flow - how it impinges on the information industry". ASLIB Prowedings38 : 257-261. 1987.

Meadow, C.T. Theanalysis ofinfomationrenieal. New Y ork: John Wiley. 1967.

Morales Campos. E. Pinmer seminaniosdarePdíticas Naaionales deInformaiónparalainvestigaiónyed desamdla México, D.F.:CUIB/ UNAM. 1990.

Mowlana, H. Gldbal informationandwoddcommmication: newfrontiessin intemational relations New Y ork: Longman. 1986.

Olson, E.E. "Organizational factors affecting information flow in industry". ASLIB Procedings $29: 2-11.1977$.

O ma, E. Pradical infomationpolidies houtomanageinfomationflowin organization Worchester: G ower. 1990.

Pao, M.L. Conepts of information renieal. Englewood, Col.: Libraries Unlimited. 1989.

Raisbeck, G. Infomation thery: anintroduction for saientist and engineers Cambridge, Mass.: MIT. 1963.

Renaud,J.L. "A conceptual framework for examination of transborder data flows". Information Socidy. 4 : 145-185. 1986.

Shannon, C. y Weaver, W. Themathematical theryof communicationUrbana,Chicago, London: University of Illinous Press. 1949.

Spink, A. "Information Science in sustainable development and deindustrialization". Infomation Research 5. 1999.

Suprenant. T. "Global threats to information". En Williams, M. An nual Reiew of Infomation Saieneand Tedndogy

Suprenant, T. Problems and trends in international and communication policies. InformationProcessingandManagenett. 23: 47-63.1987.

Vickers, P.H. Common problems of documentary information, tranfer, storage and retrieval in industrial organizations.Jaumal of Doumetation 39 : 217-229.1983.

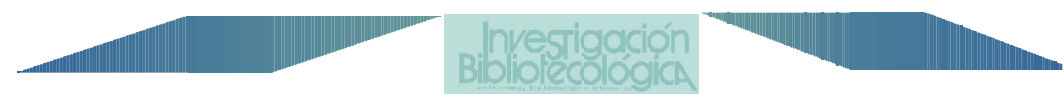

